\title{
ESTUDO COMPARATIVO ENTRE AS PROVAS DE ELISA E IMUNOFLUORESCÊNCIA INDIRETA (IFI) PARA DETECTAR ANTICORPOS CONTRA Babesia bovis ${ }^{1}$
}

\author{
A COMPARATIVE STUDY BETWEEN ELISA AND INDIRECT IMUNOFLUORESCENT \\ (IFI) TESTS TO DETECT ANTIBODIES AGAINST Babesia bovis
}

\author{
João Ricardo Martins ${ }^{2}$ Bartolomeu Lima Corrêa² Victor Hermes Ceresér ${ }^{2}$
}

\section{RESUMO}

\begin{abstract}
Comparou-se o desempenho de um kit de ELISA para detectar anticorpos contra Babesia bovis, em hemoparasita bovino, com o teste de Imunofluorescência Indireta (IFI) usualmente empregado em rotina sorológica. Sobre 97 amostras de soros oriundas de uma região livre de carrapatos e hematozoários, o teste de ELISA demonstrou uma especificidade de 98,9\% contra 97,9\% do teste de IFI. Ambos os testes apresentaram uma sensibilidade de $100 \%$ quando utilizados sobre 22 amostras de soro de bovinos experimentalmente infectados com B. bovis. Os resultados obtidos sobre 1560 amostras colhidas à campo, mostraram uma concordância de 90,1\% (1406/1560) entre amostras positivas e negativas, enquanto que 4,2\% (66) foram positivas para IFI e negativas para ELISA e 5,6\% (88) foram negativas para IFI e positivas para ELISA.
\end{abstract}

Palavras-chave: sorologia, Babesia bovis, ELISA, IFI.

\section{SUMMARY}

Performance of an ELISA kit for detecting antibodies to Babesia bovis, a bovine haemoparasite, was compared with the Indirect Fluorescent Antibody Test (IFAT) used in serological routine. Over 97 sera samples from a free tick area, ELISA showed an specificity of $98.9 \%$ against $97.9 \%$ obtained by IFAT. Both tests showed a sensitivity of $100 \%$ when compared over 22 sera samples from experimentally infected bovine with $\boldsymbol{B}$. bovis. Results obtained with 1560 field samples showed an agreement of $90.1 \%$ (1406/1560) between positive and negative samples while $4.2 \%$ (66) were positives to IFAT and negatives to ELISA, and 5.6\% (88) were negatives to IFAT and positives to ELISA.
Key words: serology, Babesia bovis, ELISA, IFAT

\section{INTRODUÇÃO}

A babesiose bovina no Brasil e demais países sul-americanos é uma enfermidade causada pelos protozoários Babesia bovis e B. bigemina, sendo o carrapato Boophilus microplus, o único vetor conhecido (GUGLIELMONE, 1995). Estes agentes diferem entre si com relação a patogenicidade e a alguns aspectos biológicos. As infecções por Babesia sp são classicamente diagnosticadas através da visualização direta de estágios intra-eritrocíticos por meio de microscópio ótico comum. Entretanto, quando os níveis de parasitemia são muito baixos, infecções latentes ou subclínicas são difíceis de serem demonstradas. A detecção de anticorpos específicos no soro dos portadores, foi uma alternativa encontrada para identificar bovinos nestas condições. A importância econômica da babesiose está relacionada com elevada mortalidade e morbidade, especialmente de bovinos adultos primo-infectados. Introduzir bovinos oriundos de áreas livres de babesiose para áreas endêmicas, onde o vetor $\boldsymbol{B}$. microplus está presente, exige a adoção de medidas profiláticas obrigatórias, tais como imunização, a fim de se evitar surtos da enfermidade.

\footnotetext{
${ }^{1}$ Projeto financiado pela Fundação de Amparo à Pesquisa do Estado do Rio Grande do Sul - FAPERGS

Médico Veterinário, MsC, FEPAGRO, Centro de Pesquisas Veterinárias Desidério Finamor. Caixa Postal 47, 92990-000 - Eldorado Sul, RS.
} 
A identificação de bovinos portadores de anticorpos contra B. bovis constitui um importante auxílio para o conhecimento da epidemiologia deste hemoparasita. Os testes sorológicos que têm sido utilizados para detectar anticorpos incluem o teste de Fixação de Complemento (MAHONEY, 1962), Imunofluorescência Indireta (ROSS \& LOHR, 1968) e Hemoaglutinação Indireta (GOODGER, 1971). Mais recentemente, testes imunoenzimáticos (ELISA) têm sido aplicados no diagnóstico sorológico de inúmeras infecções por hemoparasitas de interesse médico e veterinário (VOLLER et al., 1979). Estes testes têm demonstrado maior especificidade do que os utilizados anteriormente (TODOROVIC \& CARSON, 1981). BARRY et al. (1982) descreveram uma comparação entre os testes de ELISA e imunofluorescência indireta (IFI) para detectar anticorpos contra $\boldsymbol{B}$. bovis, com amostras de soros conhecidas e encontraram mais de 95\% de concordância entre os dois métodos, sendo a prova de ELISA mais sensível do que IFI. WALTISBUHL et al. (1987) relataram um incremento na sensibilidade no teste de ELISA através do uso da enzima peroxidase em substituição a fosfatase alcalina. JOHNSTON et al. (1973) descreveram uma técnica de IFI, a qual, com algumas modificações, está sendo usada no Laboratório de Parasitologia do CPVDF. As vantagens descritas do teste de ELISA em relação ao IFI, estão relacionadas ao fato do teste ser quantitativo, não objeto de interpretação subjetiva, e apresentar um maior potencial de processamento de exames em um período menor de tempo, além de ser altamente específico.

Neste trabalho, descreve-se uma comparação entre um teste de ELISA, apresentado sob a forma de um kit e IFI na detecção de anticorpos e discute-se a viabilidade do sistema de ELISA.

\section{MATERIAIS E MÉTODOS}

\section{Amostras de soros de campo}

Foram colhidas 1560 amostras de soro bovino em duas regiões consideradas endêmicas para B. bovis no Rio Grande do Sul: municípios de Livramento ( $30^{\circ} 53^{\prime} 18^{\prime \prime}$ Lat $\mathrm{S} ; 55^{\circ} 31^{\prime}$ 56" Long O) e Bagé ( $31^{\circ} 20^{\prime} 13^{\prime \prime}$ Lat.S; 54 06' 21" Long. O). As amostras foram armazenadas à $-20^{\circ} \mathrm{C}$ e mantidas catalogadas até a execução dos testes.

\section{Soros padrões}

Para verificar a especificidade do teste de ELISA, foram utilizadas como controle negativo, 97 amostras de soros, colhidas em uma área livre de hematozoários no RS (Santa Vitória do Palmar, $33^{\circ}$ 31'14" lat. S; 53०21'47" long. O) e negativos sorologicamente através de IFI. Também foram realizados exames microscópios, através de esfregaços de sangue corados por Giemsa, nestes animais, os quais demonstraram a ausência de hemoparasitas circulantes.

Foram colhidas 22 amostras de sangue de bovinos experimentalmente infectados com B. bovis, as quais foram utilizadas como referência no teste após confirmação da presença de hemoparasitos através de visualização por microscopia.

\section{Preparação do antígeno para Imunofluorrescência Indireta (IFI)}

Um terneiro com 6 meses de idade, previamente esplenectomizado, foi inoculado com B. bovis, via intravenosa, com 10 milhões de parasitas $/ \mathrm{mm}^{3}$. No pico da parasitemia (dia 10;0,1\% de eritrócitos infectados), $100 \mathrm{ml}$ de sangue foi retirado e imediatamente homogeneizado com anticoagulante (citrato de sódio, $13,5 \%)$. Este material foi lavado 2 vezes em solução tampão fosfato (PBS) e centrifugado a $1000 \mathrm{~g}$, durante 10 minutos. O sedimento foi passado através de um pó de celulose fibrosa (CF 11, Whatman) e inoculado, via intravenosa, em um segundo bovino esplenectomizado. Quando a parasitemia alcançou 3-5\%, 500 $\mathrm{ml}$ de sangue foi retirado e homogeneizado com Citrato de sódio, numa relação de 7/1 (sangue/citrato de sódio). $O$ sangue assim obtido foi lavado 3 vezes com PBS (1000g, 15 minutos). Os eritrócitos lavados foram ressuspendidos em PBS e ajustado o hematócrito para $50 \%$. Esfregaços finos em lâminas para microscopia foram realizados a partir desta suspensão, secos em temperatura ambiente, envoltos em papel alumínio e estocados a $-20^{\circ} \mathrm{C}$.

\section{Procedimentos para o teste de Imunofluorescência Indireta (IFI)}

O teste de IFI foi realizado de acordo com a descrição de JOHNSTON et al. (1973), com algumas adaptações, utilizando-se a diluição do soro em PBS de 1: 40. O conjugado (Anti -IgG bovina, produzida em coelho - "Sera lab", marcado com isoticianato de fluoresceína) foi empregado na diluição de 1/60 em solução tampão fosfato. 


\section{Teste de ELISA}

Os reagentes para esta prova foram fornecidos pela Agência Internacional de Energia Atômica (IAEA), Vienna, Austria. Eles foram utilizados conforme as especificações contidas no manual elaborado para esta finalidade ("ELISA kit for detection of B. bovis") sendo que foram empregadas microplacas Linbro, 96 orifícios, fundo plano (Flow Laboratories, EUA). $O$ antígeno foi diluido $1 / 600$, em solução tampão carbonato bicarbonato, $\mathrm{pH} \mathrm{9,6} \mathrm{e} \mathrm{o} \mathrm{soro} \mathrm{a} \mathrm{testar,}$ $1 / 200$, em PBS com $0,05 \%$ de Tween- 20 . O conjugado anti-IgG bovina, marcado com peroxidase foi utilizado na diluição de 1/9000 em PBS. O substrato empregado foi OPD (Ortophenilenodiamine) e para interromper a reação, uma solução $1 \mathrm{~N}$ de ácido sulfúrico. Procedeu-se a leitura das microplacas na densidade ótica de 492nm, em um leitor de microplacas Titertek Multiskan.

\section{RESULTADOS E DISCUSSÃO}

Os resultados obtidos com as técnicas de ELISA e IFI para detectar anticorpos contra $\boldsymbol{B}$. bovis sobre 1560 amostras colhidas à campo, são apresentadas na Figura 1. do positivo para IFI $(4,2 \%)$ e negativas para ELISA e 88 amostras que foram negativas para IFI $(5,6 \%)$ e positivas para ELISA.

$O$ teste em 97 amostras negativas, previamente conhecidas, revelou a especificidade de 97,9 (95 soros) para IFI e 98,9 (96 soros) para ELISA. Os 22 soros provenientes de bovinos infectados com B. bovis foram positivos em ambos os testes.

A lavagem dos eritrócitos e passagem pelo CF 11, previamente à inoculação em um segundo terneiro esplenectomizado, pareceu abreviar o período de aparecimento da parasitemia por B. bovis. A inoculação de leucócitos do primeiro bovino no segundo foi reduzida acentuadamente com este procedimento, diminuindo-se a produção imediata de anticorpos e diminuindo a possibilidade da ocorrência de soros falsos positivos. Uma parasitemia de $7 \%$ de $\boldsymbol{B}$. bovis foi conseguida no segundo dia após a inoculação com esta prática.

Ambos os testes mostraram uma elevada percentagem de especificidade e sensibilidade mas os resultados com as amostras de campo foram levemente diferentes. O número de amostras testadas para comprovar a sensibilidade foi pequeno, sendo necessário processar um maior número para se concluir sobre a mesma. É recomendável a titulação destes soros infectados, utilizando-se ambos os testes, para se conhecer melhor o comportamento destas amostras.

Uma das razões para explicar os $9,9 \%$ de

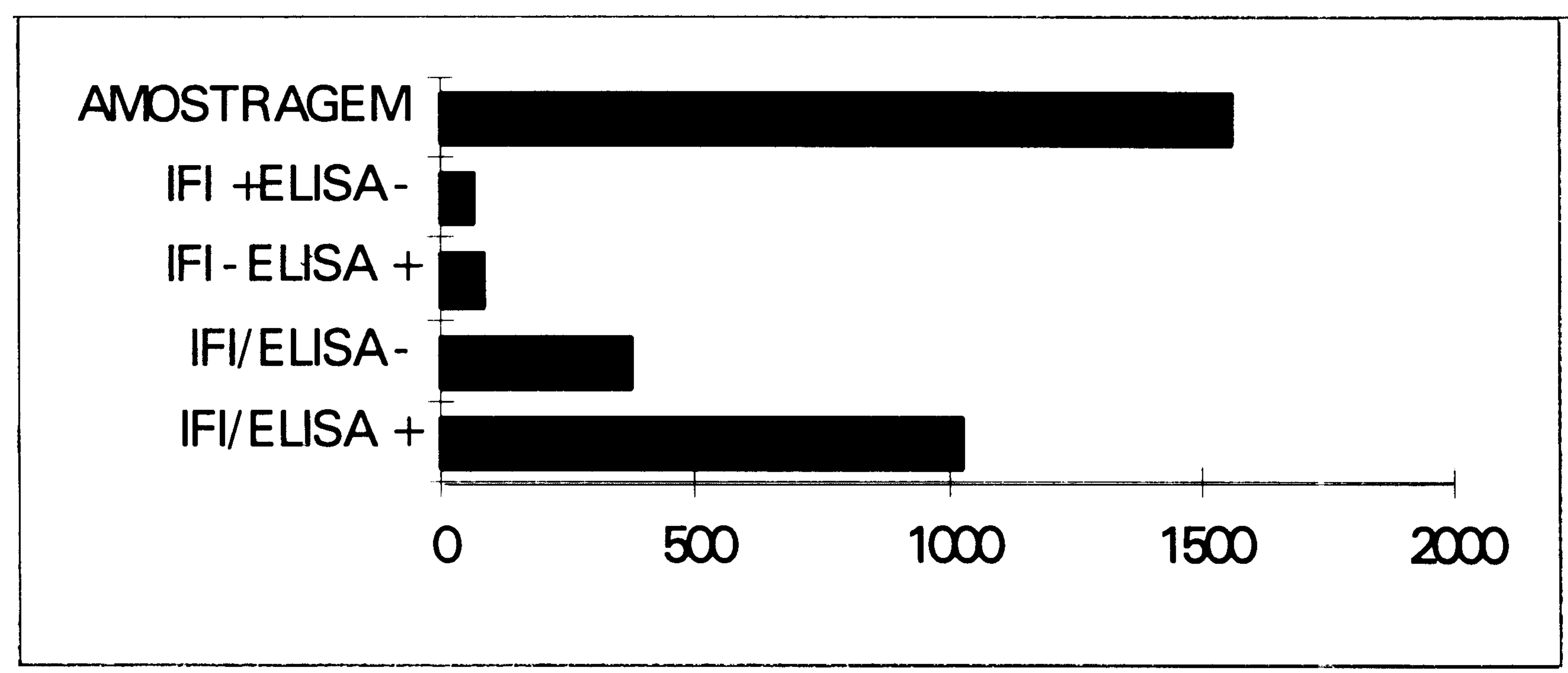

$\mathrm{N}^{\circ}$ de amostras

Figura 1. Resultados de testes sorológicos para detectar anticorpos contra Babesia bovis através dos testes de imunoenzimáticos (ELISA) e Imunofluorescência Indireta IFI). resultados diferentes entre os testes de ELISA e IFI pode ser reação cruzada com outros hemoparasitas, pois uma infecção con corrente pode ter contribuído para estas discrepâncias entre estas provas sorológicas. Reações consideradas como falsas positivas para $\boldsymbol{B}$. bovis foram observadas por WALTISBUHL et al. (1987) em soros de animais infectados com Anaplasma marginale. $\mathrm{O}$ teste de ELISA tem sido relatado como mais sensível do que IFI (BARRY et al, 1982; WALTISBUHL et al., 1987) e isto pode explicar o número levemente superior de amostras positivas detectadas por esta técnica $(88$ positivas para ELISA e negativas

Houve um percentual de concordância de $90,1 \%(1406 / 1560)$ de resultados positivos e negativos em ambos os testes. Os restantes $9,9 \%$ foram representados por 66 amostras que apresentaram resulta- para IFI), no presente trabalho.

É universalmente aceito que o ELISA é um teste imunoenzimático que permite a realização de um número maior de testes em um mesmo período, tem 
sua avaliação de forma quantitativa, e apresenta uma maior sensibilidade. Todos este aspectos foram comprovados neste estudo e a observação destes pontos é fundamental quando se pretende realizar estudos epidemiológicos numa região como o Rio Grande do Sul, onde a babesiose é endêmica na maior parte do Estado.

\section{REFERÊNCIAS BIBLIOGRÁFICAS}

BARRY, D.N., RODWELL, B.J., TIMMS, P., et al. A microplate enzyme immunoassay for detecting and measuring antibodies to Babesia bovis in cattle serum. Australian Veterinary Journal, v. 59, p. 136-140, 1982.

GOODGER, B.V. Preparation and preliminary assessment of purified in the passive haemagglutination test for bovine babesiosis. Australian Veterinary Journal, v. 47, p. 251-256, 1971.

GUGLIELMONE, A.A. Epidemiology of babesiosis and anaplasmosis in South and Central America. Veterinary Parasitology, v. 57 , p. $109-119,1995$
JOHNSTON, L.A.Y., PEARSON, R.D., LEATCH, G. Evaluation of an Indirect Fluorescent Antibody Test for detecting Babesia argentina infection in cattle. Australian Veterinary Journal, v. 49 , p. $373-377,1973$.

MAHONEY, D.F. Bovine babesiosis: Diagnosis of infection by a Complement Fixation Test. Australian Veterinary Journal, v. 38, p. 48-52, 1962.

ROSS, J.P., LOHR, K.F. Serologic diagnosis of Babesia bigemina infection in cattle by the Indirect Fluorescent Antibody Test. Research in Veterinary Science, v. 9, 557-562, 1968.

TODOROVIC, R.A., CARSON, C.A. Methods for measuring the immunological response to Babesia. In: RISTIC, M. \& KREIER, J. Babesiosis. London: Academic Press, p. 381-408, 1981.

VOLLER, A., BIDWELL, D.E., BOOLETT, A. The enzyme linked immunosorbent assay (ELISA). A guide with abstract of microplate applications. Dynatech Europe, Guernsey, GB, 1979.

WALTISBUHL, D.J., GOODGER, B.V., WRIGHT, I.G., et al. An enzyme linked immunosorbent assay to diagnose Babesia bovis infection in cattle. Parasitology Research, v. 73, p. 126-131, 1987.

Ciência Rural, v. 26, n. 1, 1996. 